\title{
Comparative Analysis of Minimum Wage in Five Provinces in Northwest China
}

\author{
Cai Yujie ${ }^{1,2}$, Li Xiuyu $^{2} \&$ Tao Yuhong ${ }^{3}$ \\ ${ }^{1}$ School of Economics, Central University of Finance and Economics, Beijing, China \\ ${ }^{2}$ Business College, Xinjiang Normal University, Xinjiang, China \\ ${ }^{3}$ Preparatory Education College, Xinjiang Normal University, Xinjiang, China \\ Correspondence: Li Xiuyu, Business College, Xinjiang Normal University, No. 100, guanjing Road, Shuimogou \\ street, Shuimogou District, Urumqi, Xinjiang, China. Tel: 1-556-375-1097. E-mail: 1067266498@qq.com
}

Received: November 17, 2019

Accepted: December 4, 2019

Online Published: December 15, 2019

doi:10.5539/ijef.v12n1p1

URL: https://doi.org/10.5539/ijef.v12n1p1

\begin{abstract}
Absrtact
The minimum wage system is an important means to guarantee the daily life of low-income workers. Through the comparative analysis of the minimum wage system, the minimum wage level and the proportion of the minimum wage standard in the local per capital GDP, average wage and per capital consumption expenditure in five Chinese northwest provinces, it is found that the development process of the minimum wage system in the five northwest provinces is similar, the overall minimum wage level difference is small, but the difference in the province is gradually increasing and the guarantee level for low-income workers needs to be improved.
\end{abstract}

Keywords: five northwest provinces, minimum wage system, minimum wage level

\section{Introduction}

The minimum wage refers to the minimum level of remuneration that the employer must pay the employee to perform his work obligations and provide normal work within the working hours stipulated by law or signed by both parties according to law, which excludes the overtime payment for extended working hours and special working environment and conditions such as medium shift, night shift, high temperature, low temperature, underground, toxic and harmful allowances, welfare benefits for workers as stipulated by laws and regulations, etc. The minimum wage system is a labor security system (Zhaozhou, Fengyun, Zhangjin et al., 2006) in which the employees can obtain the minimum cost required to maintain their basic needs (generally refer to the survival needs) in the form of legislation under the premise of providing normal work during legal working hours. The minimum wage system is an important means for the government to ensure the labor income of low-income groups (Fengming \& Shiwei, 2018). The labor supply behavior of workers is the result of the interaction of income effect and substitution effect (Robins, 1903). Under the low-income environment, the labor time of workers decreases first, then increases, then decreases with the increase of wage level (Dessing, 2002), that is, the "Inverted S" shape Labor Supply Curve. Therefore, there is a significant difference in the impact of increasing or reducing the income of low-income groups on the supply behavior of workers (Fengming \& Shiwei, 2018).

The five provinces in Northwest China( hereafter FPNC) refer to Shanxi, Xinjiang Uygur Autonomous Region (hereafter Xinjiang), Qinghai, Gansu and Ningxia Hui Autonomous Region (hereafter Ningxia) all of which belong to the underdeveloped regions in China and are also the key provinces of the western development strategy (Lin, Xinshu, \& Cuijin, 2011). In this paper, taking FPNC as the research object, we will sort out and analyze the relevant data of the minimum wage published on the website of the Department of human resources and social security of the FPNC and compare the differences between the minimum wage systems, the current situation of the minimum wage level and the adjustment of the relevant economic indicators.

\section{Comparison of the Minimum Wage System in the FPNC}

The development process of the minimum wage system in the FPNC, the current situation of the division of regional categories and the contents included show the following characteristics:

First, the development process of the minimum wage system is similar. The implementation time of the system is 
basically the same. In 1996, Gansu Province started to implement the minimum wage system, and the other four provinces started to implement it in 1995.

Table 1. Comparison and statistics of the minimum wage system of the five northwest provinces

\begin{tabular}{cccccc}
\hline & Inner Mongolia & Gansu & Qinghai & Ningxia & Xinjiang \\
\hline Setup Time & 1995 & 1996 & 1995 & 1995 & 1995 \\
Regional Categories & Four & Four & One & Three & Four \\
Social Security & Four Risks and One Gold & Not Specified & Not Specified & Including Social Security & Two Forms \\
\hline
\end{tabular}

Secondly, there are great differences in the classification of regional categories. Among the FPNC, only Qinghai has one regional division standard, that is, there is no difference in the minimum wage standard of the whole province; Ningxia divides the whole province into three categories, while Xinjiang, Inner Mongolia and Gansu are all divided into four categories.

Third, there are great differences in the contents of the minimum wage standard. Inner Mongolia includes Four Insurances and House Accumulation Fund in addition to Maternity Insurance; Xinjiang includes Three Insurances and Housing Accumulation Fund; Ningxia includes all kinds of social insurance premiums that employees should pay according to law; Qinghai and Gansu have not made specific explanations for the contents of the minimum wage standard.If the minimum wage standard includes the social insurance expenses and Housing Accumulation Fund that should be paid by individual employees, that is, after the employer withholds the Social Insurance Expenses and Housing Accumulation Fund that should be paid by individual employees, which means the actual wage will be lower than the legal minimum wage standard. Comparatively speaking, Xinjiang's minimum wage system is more clear, which can avoid the employers' misinterpretations of the connotations of the minimum wage standard or the workers' own negligence to damage the rights and interests of workers.

\section{Comparison of the Minimum Wage Level of the FPNC}

\subsection{Comparison of the Minimum Wage Gap in Five Regions of Northwest China}

Table 2. Statistics of minimum wage level and its growth rate in five regions of Northwest China (RMB,\%)

\begin{tabular}{|c|c|c|c|c|c|c|c|c|c|c|c|}
\hline & & \multicolumn{2}{|c|}{ Inner Mongolia } & \multicolumn{2}{|c|}{ Gansu } & \multicolumn{2}{|c|}{ Qinghai } & \multicolumn{2}{|c|}{ Ningxia } & \multicolumn{2}{|c|}{ Xinjiang } \\
\hline \multirow{3}{*}{$\begin{array}{l}\text { Average deviation } \\
\text { in Province }\end{array}$} & 1996 & \multirow{2}{*}{\multicolumn{2}{|c|}{$\begin{array}{c}20 \\
100 \\
\end{array}$}} & \multirow{2}{*}{\multicolumn{2}{|c|}{$\begin{array}{l}20 \\
50 \\
\end{array}$}} & \multirow{2}{*}{\multicolumn{2}{|c|}{$\begin{array}{c}10 \\
0 \\
\end{array}$}} & \multirow{2}{*}{\multicolumn{2}{|c|}{$\begin{array}{l}20 \\
90\end{array}$}} & \multicolumn{2}{|c|}{10.6} \\
\hline & \multirow[t]{2}{*}{2017} & & & & & & & & & 120 & \\
\hline & & $\begin{array}{l}\text { Minimum } \\
\text { Wage }\end{array}$ & $\begin{array}{l}\text { Growth } \\
\text { Rate }\end{array}$ & $\begin{array}{l}\text { Minimum } \\
\text { Wage }\end{array}$ & $\begin{array}{c}\text { Growth } \\
\text { Rate }\end{array}$ & $\begin{array}{l}\text { Minimum } \\
\text { Wage }\end{array}$ & $\begin{array}{c}\text { Growth } \\
\text { Rate }\end{array}$ & $\begin{array}{l}\text { Minimum } \\
\text { Wage }\end{array}$ & $\begin{array}{c}\text { Growth } \\
\text { Rate }\end{array}$ & $\begin{array}{l}\text { Minimum } \\
\text { Wage }\end{array}$ & $\begin{array}{c}\text { Growth } \\
\text { Rate }\end{array}$ \\
\hline \multirow{23}{*}{$\begin{array}{l}\text { Minimum Wage } \\
\text { Level }\end{array}$} & 1995 & 160 & - & 160 & - & 185 & - & 160 & - & 165 & - \\
\hline & 1996 & 160 & 0.00 & 160 & 0.00 & 185 & 0.00 & 160 & 0.00 & 203 & 23.03 \\
\hline & 1997 & 190 & 18.75 & 160 & 0.00 & 185 & 0.00 & 160 & 0.00 & 203 & 0.00 \\
\hline & 1998 & 190 & 0.00 & 160 & 0.00 & 185 & 0.00 & 160 & 0.00 & 203 & 0.00 \\
\hline & 1999 & 219 & 15.26 & 160 & 0.00 & 199 & 7.57 & 160 & 0.00 & 230 & 13.30 \\
\hline & 2000 & 247 & 12.79 & 243 & 51.88 & 240 & 20.60 & 160 & 0.00 & 310 & 34.78 \\
\hline & 2001 & 247 & 0.00 & 260 & 7.00 & 240 & 0.00 & 173 & 8.13 & 323 & 4.19 \\
\hline & 2002 & 263 & 6.48 & 260 & 0.00 & 240 & 0.00 & 320 & 84.97 & 360 & 11.46 \\
\hline & 2003 & 310 & 17.87 & 260 & 0.00 & 240 & 0.00 & 320 & 0.00 & 360 & 0.00 \\
\hline & 2004 & 355 & 14.52 & 320 & 23.08 & 268 & 11.67 & 348 & 8.75 & 380 & 5.56 \\
\hline & 2005 & 340 & -4.23 & 320 & 0.00 & 350 & 30.60 & 350 & 0.57 & 390 & 2.63 \\
\hline & 2006 & 420 & 23.53 & 348 & 8.75 & 400 & 14.29 & 404 & 15.43 & 500 & 28.21 \\
\hline & 2007 & 480 & 14.29 & 375 & 7.76 & 450 & 12.50 & 443 & 9.65 & 555 & 11.00 \\
\hline & 2008 & 590 & 22.92 & 514 & 37.07 & 543 & 20.67 & 525 & 18.51 & 660 & 18.92 \\
\hline & 2009 & 590 & 0.00 & 560 & 8.95 & 590 & 8.66 & 525 & 0.00 & 660 & 0.00 \\
\hline & 2010 & 690 & 16.95 & 594 & 6.07 & 647 & 9.66 & 613 & 16.76 & 742 & 12.42 \\
\hline & 2011 & 814 & 17.97 & 695 & 17.00 & 798 & 23.34 & 783 & 27.73 & 905 & 21.97 \\
\hline & 2012 & 954 & 17.20 & 864 & 24.32 & 923 & 15.66 & 925 & 18.14 & 1085 & 19.89 \\
\hline & 2013 & 1088 & 14.05 & 1063 & 23.03 & 1060 & 14.84 & 1158 & 25.19 & 1265 & 16.59 \\
\hline & 2014 & 1275 & 17.19 & 1234 & 16.09 & 1193 & 12.55 & 1254 & 8.29 & 1340 & 5.93 \\
\hline & 2015 & 1420 & 11.37 & 1365 & 10.62 & 1260 & 5.62 & 1400 & 11.64 & 1403 & 4.70 \\
\hline & 2016 & 1490 & 4.93 & 1395 & 2.20 & 1260 & 0.00 & 1400 & 0.00 & 1490 & 6.20 \\
\hline & 2017 & 1540 & 3.36 & 1483 & 6.31 & 1420 & 12.70 & 1443 & 3.07 & 1490 & 0.00 \\
\hline Adjustment Times & & 13 & & 10 & & 9 & & 12 & & 11 & \\
\hline
\end{tabular}


As shown in Table 2, the differences among the five provinces in Northwest China are gradually increasing. In 1996, the minimum wage gap in Qinghai was the smallest, with an average difference of 10 yuan, followed by 10.6 yuan in Xinjiang, and 20 yuan in Inner Mongolia, Gansu and Ningxia. In 2017, the average difference in Xinjiang's minimum wage standards was up to 120 yuan, followed by Inner Mongolia. It can be seen from the above data that there are great differences in the economic development of various regions in Xinjiang.

\subsection{Comparison of the Minimum Wage Level of the FPNC}

The minimum wage regulation stipulates that the minimum wage standard shall be adjusted at least once every two years, but there is no specific adjustment time and the date of annual adjustment of the minimum wage standard in each region is inconsistent. Therefore, the weighted average method is used to calculate the minimum wage standard of the FPNC. For example, in June 2013, Xinjiang minimum wage standard was 1340 RMB yuan and in August 2015, 1340 RMB yuan. So in 2015, Xinjiang minimum wage standard $(1340 * 7+$ $1490 * 5) / 12=1403$ RMB yuan.

As shown in Table 2, there is little difference in the minimum wage level among the FPNC. In 1995, it was 160 RMB yuan in Inner Mongolia, Gansu and Ningxia, 185 RMB yuan in Qinghai and 165 yuan in Xinjiang; in 2017, it was 154 RMB yuan in Inner Mongolia, 1483 RMB yuan in Gansu, 1420 RMB yuan in Qinghai, 1443 RMB yuan in Ningxia and 1490 RMB yuan in Xinjiang. From the above data, we can see that there is little difference in the economic development level of the five Chinese northwest provinces.

\section{Comparison of the Adjustment of the Minimum Wage in the Five Chinese Northwest Provinces}

As shown in Table 2, on the whole, there is little difference in the change of the minimum wage level in the five northwest provinces, but there is a large difference in the adjustment frequency. From 1995 to 2017, the minimum wage in Inner Mongolia, Gansu, Qinghai, Ningxia and Xinjiang increased by 1380 RMB yuan, 1323 RMB yuan, 1235 RMB yuan, 1283 RMB yuan and 1325 RMB yuan respectively, with the growth rates of $862.5 \%, 826.88 \%, 667.57 \%, 801.88 \%$ and $803.03 \%$ respectively. Since the implementation of the minimum wage system, the frequency of adjustment of the minimum wage level in Inner Mongolia has been the highest. Except for the three consecutive years from 1999 to 2002 when the minimum wage standard was not adjusted, the minimum wage standard in other years has been improved. The increment from 2010 to 2015 is more than 100 RMB yuan, and the growth rate is more than $10 \%$. The average annual growth rate and adjustment frequency of the minimum wage standard in Qinghai are at a low level, and the minimum wage standard has not been adjusted in 2000-2003. In 2013, Ningxia's minimum wage standard rose by 233 yuan, which was the highest increase in absolute value of the minimum wage standard in five northwest provinces. In 2006, Xinjiang's minimum wage rose 110 yuan, which was far higher than the other four provinces. From 2014 to 2017, the rise rate of Xinjiang minimum wage standard was lower than that of the other four provinces in the same period. In 2009 and 2017, there was no change in Xinjiang's minimum wage standard. From the above data, we can see that the rapid development of Xinjiang's economy, however, the income of workers is lagging behind, and the living standards of workers are not effectively guaranteed.

From the above analysis, we can see that the change tracks of the minimum wage level in the five northwest provinces are basically the same.

\section{Comparison of the Relationship Between Minimum Wage and Related Economic Indicators in the FPNC}

\subsection{Minimum Wage and Per Capita GDP}

The ratio of the minimum wage to the per capita GDP reflects the rationality of the minimum wage standard (Xuepeng \& Lei, 2018), which represents the proportional relationship between the income of low-income workers and the per capita social wealth (Meiyan, 2013). As shown in Figure 1, the ratios of minimum wage standard to GDP in the FPNC are quite different. Gansu Province is the highest, and each year during the statistical period is higher than the other four provinces; Inner Mongolia is the lowest, showing the track of first decline and then rise; Xinjiang's range of change is relatively small, basically stable at about $40 \%$. Qinghai and Ningxia showed a downward trend, that is, the proportion of low-income workers' income in per capita social wealth creation gradually decreased, which led to the gradual expansion of the income gap. 


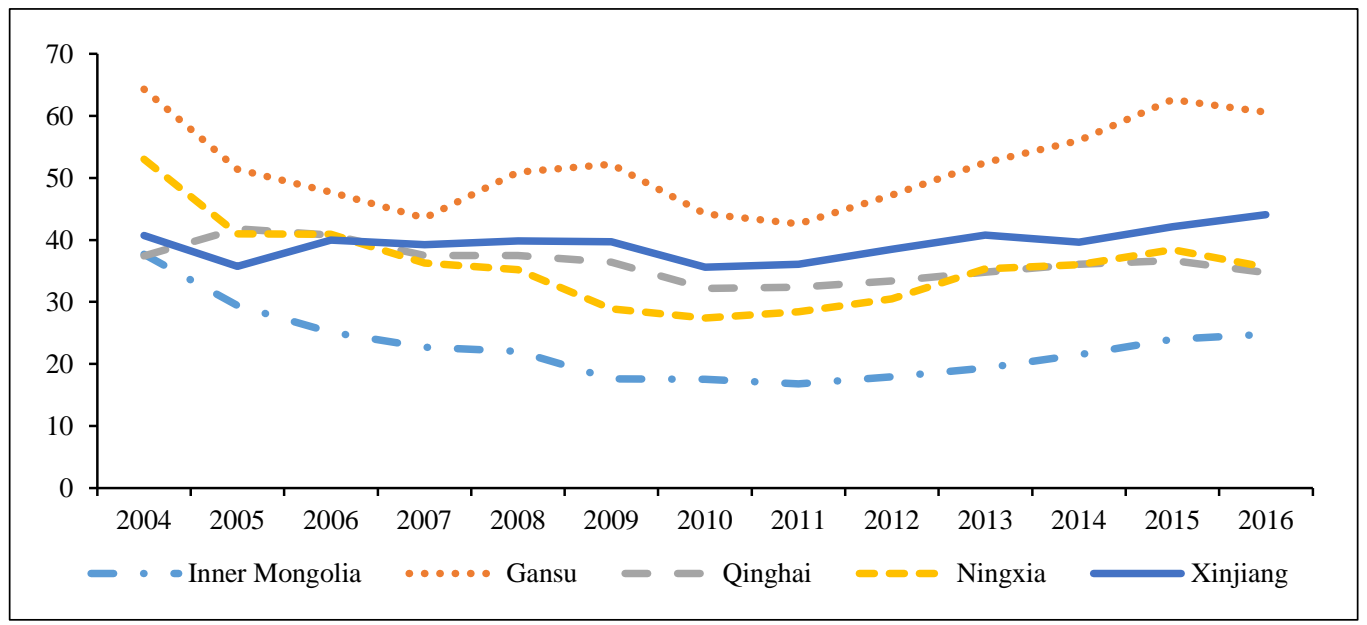

Figure 1. Statistical chart of the proportion of minimum wage to GDP in the five Northwest Provinces (\%)

\subsection{Minimum Wage and Average Wage}

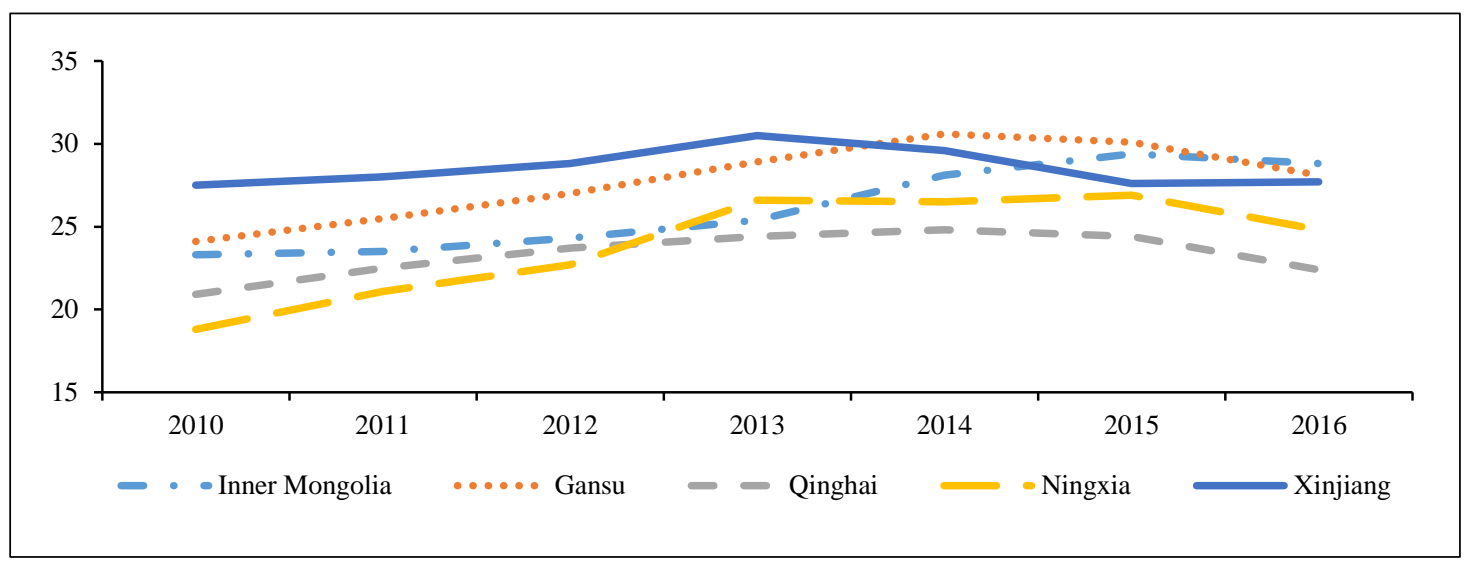

Figure 2. Ratio of minimum wage to average monthly wage of urban employees in five Northwest Provinces (\%)

The ratio of the minimum wage to the average wage indicates the gap between the low-income group and the average social income level (Yong, 2016). The average social wage is an important basis for determining the minimum wage standard (Jian, Yufeng, \& Ziqi, 2018). It is generally believed that the minimum wage is more reasonable when it accounts for $40 \%-60 \%$ of the average wage (Yong, 2016). Based on this standard, this paper analyzes and compares the rationality of the minimum wage setting in the FPNC.

As shown in Figure 2, from 2010 to 2016, the ratio of the minimum wage in the FPNC to the average wage of urban employees in each province was lower than $30 \%$, which is far below the international standard, that is, the minimum wage in the FPNC was low. At the same time, in addition to Xinjiang, the proportion of the minimum wage in per capita income of the other four provinces in Northwest China rose firstly and then declined, that is to say, compared with the development speed of China's economy, the basic living conditions of low-income workers in Inner Mongolia, Qinghai, Gansu and Ningxia were relatively backward. 


\subsection{Minimum Wage and Consumption Expenditure Per Capita}

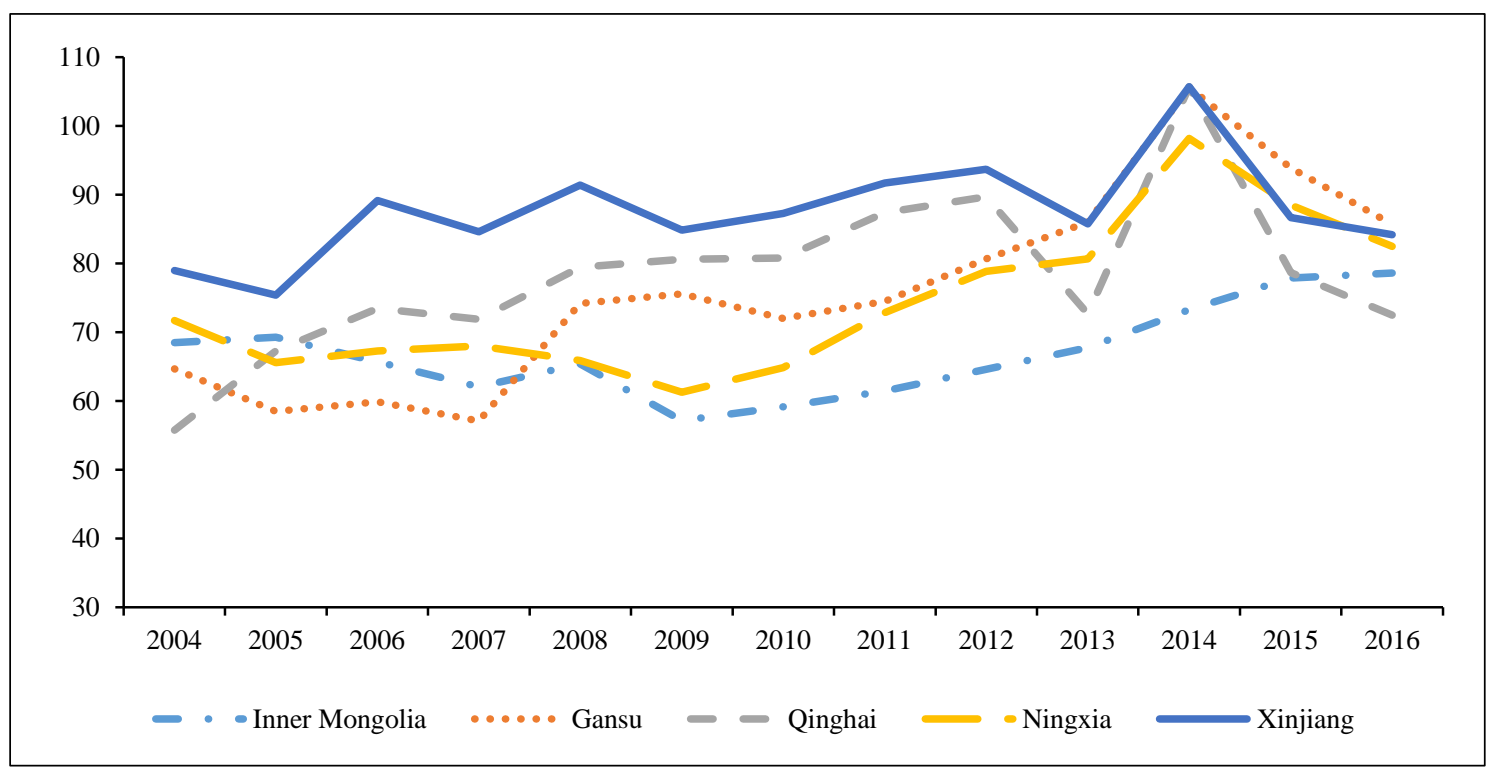

Figure 3. Statistical chart of the ratio of the minimum wage standard to the per capita consumption expenditure in the five Northwest Provinces (\%)

After the reform and opening up, China's national economy has achieved sustained, stable and rapid development. At the same time, China's consumption expenditure per capita also continues to rise (Min \& Xiguang, 2019). The ratio of minimum wage to consumption expenditure per capita represents the guarantee level of minimum wage (Fengming \& Shiwei, 2018). As shown in Figure 3, the ratio of minimum wage to consumption expenditure per capita in the FPNC from 2004 to 2016 shows the following characteristics:

Firstly, the income of low-income workers in the FPNC is lower than the consumption expenditure per capita, and the gap is on the rise. In 2004, the ratios of Inner Mongolia, Gansu, Qinghai, Ningxia and Xinjiang were $68.5 \%, 64.7 \%, 55.8 \%, 71.1 \%$ and $79 \%$ respectively; in 2016 , they were $78.6 \%, 85.7 \%, 72.5 \%, 82.5 \%$ and $84.2 \%$ respectively; they increased by $10.1 \%, 21 \%, 16.7 \%, 11.4 \%$ and $5.2 \%$ respectively. It can be seen from the above data that the consumption level of low-income workers in the FPNC is far lower than the average consumption level of each province.

Secondly, Inner Mongolia has the lowest level of security for low-income people, while Xinjiang holds the highest. The minimum wage in Inner Mongolia accounts for less than $80 \%$ of consumption expenditure per capita, which is lower than other four provinces. From 2004 to 2014, the ratio of Xinjiang's minimum wage standard to the consumption expenditure per capita has been at the highest level in five , that is, Xinjiang's minimum wage standard is more able to meet the consumption expenditure of workers; from 2015 to 2016 , the ratio declined, and the level of life security for low-income workers weakened.

Thirdly, the security level of low-income workers in the FPNC needs to be improved. From 2004 to 2016 , only in 2014, the minimum wage of Gansu, Qinghai and Xinjiang was higher than their consumption expenditure per capita, that is to say, based on the average consumption expenditure level of each province in 2014, only the low-income workers in Gansu, Qinghai and Xinjiang had the ability to save, and the low-income workers in other provinces could not make ends meet.

\section{Conclusion}

Compared with the minimum wage system of the FPNC, it is found that the development patterns of the minimum wage system of five provinces in Northwest China are similar, but there are great differences in the classification of regional categories and the contents of the minimum wage standard. Compared with the minimum wage level of the FPNC, it is found that the difference of the whole minimum wage level of the FPNC is small, but the difference within the province is gradually increasing. By comparing the ratio between the minimum wage standard and the per capita GDP, average wage, consumption expenditure per capita and other indicators in the FPNC, it is found that the overall minimum wage in the FPNC is low, the level of 
protection for low-income workers needs to be improved and the ratios between the minimum wage standard and GDP are quite different.

\section{Reference Significance of the Minimum Wage System of the FPNC to Xinjiang}

\subsection{To Increase Adjustment Frequency and Fix Adjustment Date}

At present, within the environment of rapid economic development, the rising prices and inflations have put forward higher requirements for the frequency of wage rise of workers. As mentioned before, in 2017, Xinjiang did not raise the minimum wage standard, while the consumption expenditure per capita, social average wage and CPI all rose, resulting in the damage to the rights and interests of workers and the lack of basic protection of life. At the same time, speeding up the adjustment of frequency properly can provide a buffer period for enterprises, reduce the burden of enterprises and the damage to workers and social and economic development. Fixed adjustment date is conducive to improving the attention of the minimum wage system, so that the government can strengthen the publicity and supervision of the minimum wage system, so that the minimum wage system can be widely valued both by employers and workers.

\subsection{To Raise the Minimum Wage}

The consumption expenditure per capita and social average wage shall be taken into consideration in the formulation of the minimum wage standard. There are many basis for the adjustment of the minimum wage system, but most of them are fuzzy. The ratio between the minimum wage standard and the social average wage is $40 \%-60 \%$, which is more objective and controllable and the statistical caliber is relatively uniform, which reduces the subjectivity in the process of formulating the minimum wage standard. At the same time, as mentioned above, in recent years, the difference between the minimum wage standard and consumption expenditure per capita has gradually increased and the minimum wage recipients have not received effective life security. It is suggested that this factor should also be included in the basis for the establishment of the minimum wage standard.

\subsection{To Strengthen Supervision}

The minimum wage system is mainly for small enterprises and workers working in small enterprises. Workers do not know enough about the policy, and the employer's misinterpretations and evasions of the policy will all damage the policy implementation, which will damage the rights and interests of workers and harm the sound and healthy development of the economy. Therefore, to strengthen the supervision and publicity of the minimum wage system is to promote the implementation of the policy from both employers and workers, so as to maintain social equity, reduce poverty and promote development.

\section{References}

Brown, C., Gilroy, C., \& Kohen, A. (1982). The Effect of the Minimum Wage on Employment and Unemployment. Journal of Economic Literature, 20(2). https://doi.org/10.3386/w0846

Card, D., \& Krueger, A. B. (1994). Minimum Wages and Employment: A Case Study of the Fast-Food Industry in New Jersey and Pennsylvania. American Economic Review, 84(4). https://doi.org/10.3386/w4509

Chuang, Z., \& Shiwei, Z. (2009). Labor Supply Behavior of Urban Residents in China: An Empirical Study of Inverted S-type Labor Supply Curve in China's Urban Labor Market. Science of Finance and Economics, (11), 56-64.

Fengming, G., \& Shiwei, Z. (2018). The Impact of the Minimum Wage Increase on the Excessive Labor of Low-income Migrant Workers. China Population Science, (5), 42-56 + 127

Flinn, C. (2006). Minimum Wage Effects on labor Market Outcome under Search, Matching, and Endogenous Contact Rates. Economical, 74(4). https://doi.org/10.1111/j.1468-0262.2006.00693.x

Heckman, J. (1993). What Has Been Learned about Labor Supply in the Past Twenty Years? American Economic Review, 83(2).

Jian, Z., Yufeng, W., \& Ziqi, Z. (2018). Research on the Impact of Minimum Wage System on Informal Employment: Evidence from China's Provincial Dynamic Panel Data. Financial Forum, (10), 11.

Kai, C. (2007). On the Legal Perfection of China's Minimum Wage System. Wuhan: Huazhong University of Science and Technology.

Lin, L., Xinshu, G., \& Cuijin, L. (2011). Measurement and Empirical Analysis of Poverty Level of Urban Residents in Northwest China. Journal of Population, (6), 18-26. 
Linneman, P. (1982). The Economic Impacts of Minimum Wage Laws: A New Look at An Old Question. Journal of Political Economy, 90(3). https://doi.org/10.1086/261069

Lu, J., Bingchun, Q., \& Shengji, L. (2019). Labor Supply Effect of Minimum Wage System. Taxation and Economy, (2), 44-49.

Meiyan, W. (2013). Design and Implementation of China's Minimum Wage System. Macroeconomic Research, (7), 18-25+83.

Min, D., \& Xiguang, C. (2019). Population Age Structure, Wages and Regional Economic Growth: An Empirical Analysis Based on the Provincial Panel Data of China from 1995 to 2015. Modern Economic Discussion, (1), 16-24.

Neumark, D. M., \& Schweitzer, W. W. (2004). Minimum Wage Effects throughout the Wage Distribution. Journal of Human Resources, 39(2). https://doi.org/10.3368/jhr.XXXIX.2.425

Neumark, D., \& Wascher, W. (1992). Employment Effects of Minimum and Subminimum Wages: Panel Data on State Minimum Wage Laws. Industrial and Labor Relations Review, 46(1). https://doi.org/10.1177/001979399204600105

Stewart, M. B., \& Swaffield, J. K. (2008). The Other Margin: Do Minimum Wages Cause Working Hours $\begin{array}{lllll}\text { Adjustments for } & \text { Low-Wage }\end{array}$ https://doi.org/10.1111/j.1468-0335.2007.00593.x

Strobl, E. F. W. (2007). Dealing with Monopsony Power: Employment Subsidies vs. Minimum Wages. Economics Letters, 94(1). https://doi.org/10.1016/j.econlet.2006.08.005

Xuepeng, S., \& Lei, S. Empirical Analysis on the Determinants of China's Minimum Wage Standard and its Changes. Contemporary Economic Science, (5), 117-123+128.

Yihan, S., Jianguo, X., \& Baochang, X. (2018). Minimum Wage Standard and Enterprise Cost plus: Evidence from Chinese Manufacturing Enterprises. China Economic Issues, (6), 123-136.

Yong, X. (2016). A Study on the Moderation of China's Minimum Wage Level: From the Perspective of Re-estimating the Social Average Wage. Social Science, (2), 52-63.

Zhaozhou, H., Fengyun, W., ZhangJin, W. et al. (2006). Labor Wage and Social Security: Research on the Minimum Wage Survey and Statistical Calculation Model in Guangdong Province. Beijing: Economic Science Press, 2006.

\section{Copyrights}

Copyright for this article is retained by the author(s), with first publication rights granted to the journal.

This is an open-access article distributed under the terms and conditions of the Creative Commons Attribution license (http://creativecommons.org/licenses/by/4.0/). 